\title{
Utilization due to chronic obstructive pulmonary disease and its predictors: a study using the U.S. National Emergency Department Sample (NEDS)
}

Jasvinder A. Singh ${ }^{1,2,3^{*}}$ and Shaohua $\mathrm{Yu}^{2}$

\begin{abstract}
Background: Previous studies of healthcare utilization for chronic obstructive pulmonary disease (COPD) have focused on time-trends in COPD visits or COPD treatments, or the effect of hospital volume on mortality. Few data are available regarding outcomes after an ED visit (and subsequent hospitalization) for COPD, which are both very common in patients with COPD. Our objective was to assess time-trends and predictors of emergency department and subsequent inpatient health care utilization and charges associated with COPD in the U.S.

Method: We used the 2009-12 U.S. Nationwide Emergency Department Sample (NEDS) to study the incidence of ED visits and subsequent hospitalizations with COPD as the primary diagnosis. We used the 2012 NEDS data to study key patient/hospital factors associated with outcomes, including charges, hospitalization and dischage from hospital to home.

Results: ED visits for COPD as the primary diagnosis increased from 1.02 million in 2009 to 1.04 in 2010 to 1.10 million in 2012 (0.79-0.82\% of all ED visits); respective charges were \$2.13, \$2.32, and \$3.09 billion. In 2012, mean ED charges/visit were $\$ 2,812$, hospitalization charges/visit were $\$ 29,043$ and the length of hospital stay was 4.3 days. $49 \%$ were hospitalized after an ED visit. Older age, higher median income, metropolitan residence and comorbidities (diabetes, hypertension, HF, hyperlipidemia, CHD, renal failure and osteoarthritis) were associated with higher risk whereas male sex, Medicaid or self pay insurance status, hospital location in Midwest, South or West U.S. were associated with lower risk of hospitalization. $65.4 \%$ of all patients hospitalized for COPD from ED were discharged home. Older age, comorbidities (diabetes, HF, CHD, renal failure, osteoarthritis) and metropolitan residence were associated with lower odds of discharge to home, whereas male sex, payer other than Medicare, Midwest, South or West U.S. hospital location were associated with higher odds.

Conclusion: Health care utilization and costs in patients with COPD are significant and increasing. COPD constitutes a major public health burden in the U.S. We identified risk factors for hospitalization, costs, and home discharge in patients with COPD that will allow future studies to investigate interventions to potentially reduce COPD-associated utilization.
\end{abstract}

\footnotetext{
* Correspondence: Jasvinder.md@gmail.com

${ }^{1}$ Medicine Service, Birmingham VA Medical Center, Birmingham, AL, USA

${ }^{2}$ Department of Medicine at School of Medicine, and Division of

Epidemiology at School of Public Health, University of Alabama at

Birmingham (UAB), Faculty Office Tower 805B, 510 20th Street S,

Birmingham, AL 35294, USA

Full list of author information is available at the end of the article
} 


\section{Background}

Chronic obstructive pulmonary disease (COPD) is associated with significant morbidity and health care costs worldwide [1]. COPD is the third leading cause of mortality in the U.S. and affects $>12$ million Americans [2,3]. COPD was associated with $\$ 32$ billion in costs in 2010 in the U.S. [4]. It frequently leads to inability to work and mobility limitations [5], which poses high societal economic burden [6]. COPD is associated with significant decrements in quality of life [7], worst in those with higher COPD disease severity $[8,9]$. In addition to clinical burden, the inability to work due to COPD also poses high economic burden on both patients and governments [6].

Acute exacerbations of COPD are associated with significant morbidity, and decrements in quality of life $[10,11]$ and lead to frequent ED visits and hospitalizations. Studies have examined factors associated with hospitalization in patients with COPD, mostly in single-center settings or small cohorts [12-14]. One study using a nationally representative U.S. sample found that EDs with higher COPD volume had lower mortality and shorter hospital length of stay [15] compared to those with a lower volume. A previous study using the U.S. National Hospital Ambulatory Medical Care Survey (NHAMCS) from 1993 to 2005 reported 0.6 million COPD visits annually [16], consistent with the estimates reported earlier using the National emergency Department (NEDS) data [15].

Previous studies of COPD ED visits focused on timetrends in visits [17], effect of hospital volume on mortality [15] and trends in treatment [16]. Few, if any data, are available regarding outcomes after an ED visit for COPD. A recent NEDS study comparing COPD with other chronic conditions combined COPD and bronchiectasis and did not provide separate data for COPD [17]. An older study estimated 1.5 million emergency department visits in 2002 in the U.S. [18]. These Centers for Disease Control and Prevention (CDC) data are 15-years old. Thus, contemporary data related to ED and inpatient burden due to COPD in the U.S. are needed, to better understand the current COPD burden on the healthcare system. Our objective was to examine the predictors and estimates of ED and inpatient utilization due to COPD as the primary diagnosis and post-hospitalization disposition, using contemporary NEDS data.

\section{Methods}

\section{Data source and study population}

We used the discharge data from the Nationwide Emergency Department Sample (NEDS), the largest, all-payer U.S. emergency department [ED] database that contains a $20 \%$ stratified sample of ED visits from across the U.S., provided by the Healthcare Cost and Utilization Project (HCUP), Agency for Healthcare Research and Quality $[19,20]$. NEDS data is provided by the HCUP State
Emergency Department Databases (SEDD) and the State Inpatient Databases (SID) $[19,20]$ that capture the discharge information on ED visits that do not result vs. that result in an admission to the same hospital, respectively. As an example, 950 U.S. hospitals from 30 states contributed data in 2012.

NEDS is publicly available. NEDS provides appropriate weights to obtain weighted national estimates [20]. For this study, we limited analyses to patients aged 18 and older with an ED visit with COPD as the primary diagnosis. COPDrelated visits and hospitalizations were identified using the International Classification of Diseases, ninth revision, Common Modification (ICD-9-CM) code of 491.xx, 492.xx and 496.xx, which have been previously shown to be valid [21]. NEDS contains event-level data but not unique identifiers so that individuals may be represented by multiple visits in any given year. The Institutional Review Board at the University of Alabama at Birmingham (UAB) approved the study.

\section{Outcomes of interest}

We examined the following outcomes of interest: (1) ED discharge disposition (hospitalization vs.routine discharge); (2) ED charges; (3) Inpatient discharge to home (vs. other); (4) Duration of hospital stay; and (5) Total charges (ED and inpatient).

\section{Covariates}

We examined patient and hospital characteristics as covariates. These included age, sex, insurance status, residence [urban vs. rural] and annual median household income estimated using residential zip code. Hospital characteristics included geographical region [Northeast, Midwest, South and West], location in metropolitan or non-metropolitan area, and whether the hospital is teaching vs. non-teaching. For each visit in NEDS, up to 15 ICD-9-CM diagnostic codes, and nine ICD-9-CM procedure codes are provided. We pre-specified certain non-pulmonary comorbidities as potential predictors of outcomes in patients with COPD as the primary reason for ED visit/hospitalization. These comorbidities were chosen due to their common occurrence (coronary heart disease [CHD], heart failure [HF], diabetes, renal failure, hyperlipidemia, hypertension, osteoarthritis [OA], gout).

\section{Statistical analysis}

We calculated summary statistics for key outcomes associated with COPD-related ED-visits and COPD-related hospitalizations across 2009 to 2012. The original 2011 Nationwide Emergency Department Sample (NEDS) included duplicated records in the South and Midwest and a corrected 2011 dataset was not available in amended form for us to analyze. Therefore, most analyses for time-trends used 2009, 2010 and 2012 data. We used the 2012 NEDS data, as the most recent data available, 
to analyze whether patient and hospital factors were associated with outcomes of COPD-related ED visit, i.e. ED visit with COPD as the primary diagnosis (charges; hospital admission vs. not), COPD-related inpatient admission (length of stay; total charges) and disposition after inpatient admission (discharge to nursing home, total charges).

We examined patient- and hospital characteristics and comorbidities (secondary diagnoses) as potential predictors of these outcomes (see covariate section). We performed multivariable-adjusted logistic regression (discharge disposition, length of hospital stay $\geq 2$ days) or linear regression (charges, duration of hospitalization) using SAS version 9.3 (SAS corporation, Cary, NC, USA). Sensitivity analyses examined the log of hospital stay, hospital stay when dichotomized at 2 days, and the log of total hospital charges, since hospital stay and charges variables were slightly more normal distributed when log-transformed and to examine whether findings were robust or not. Sensitivity models were also performed adding asthma as a pulmonary comorbidity to main models, since it frequently accompanies COPD.

\section{Results}

\section{Clinical and demographic characteristics}

The number of ED visits for COPD increased from 1.02 million in 2009 to 1.04 in 2010 to 1.10 in 2012 (Table 1). There were similar proportions of patients across study years who were female or lived in metropolitan area. Across the study years, the primary payer, hospital region and teaching status were also similar (Table 1).

Table 1 Emergency department (ED) visits for COPD as the primary diagnosis in year 2009, 2010 and 2012 NEDS database

\begin{tabular}{|c|c|c|c|}
\hline & 2009 NEDS & 2010 NEDS & 2012 NEDS \\
\hline \#COPD ED visits (\% total) & $1,019,276(0.79)$ & $1,039,825(0.80)$ & $1,100,378(0.82)$ \\
\hline \multicolumn{4}{|l|}{ Age, in years } \\
\hline Mean (SE) & $65.99(0.15)$ & $65.82(0.13)$ & $65.49(0.13)$ \\
\hline Median (IQR) & $65.88(55.71,75.70)$ & $65.68(55.52,75.36)$ & $65.04(55.34,74.82)$ \\
\hline \multicolumn{4}{|l|}{ Sex } \\
\hline Female & $561298(55.13)$ & $573,622(55.17)$ & $608,895(55.34)$ \\
\hline \multicolumn{4}{|l|}{ Patient location (residence) } \\
\hline Micropolitan/not metro & $283,145(27.95)$ & $280,036(27.07)$ & $297,501(27.13)$ \\
\hline Metropolitan (large or small) & $729,842(72.05)$ & $754,433(72.93)$ & $798,895(72.87)$ \\
\hline \multicolumn{4}{|l|}{ Median house hold income } \\
\hline 1st quartile $(<\$ 38,999)$ & $371,277(37.46)$ & $373,961(36.88)$ & $428,687(39.81)$ \\
\hline 2nd quartile $(\$ 39,000$ to $\$ 47,999)$ & $307,056(30.98)$ & $302,423(29.83)$ & $295,576(27.45)$ \\
\hline 3rd quartile ( $\$ 48,000$ to $\$ 62999)$ & $198,385(20.01)$ & $206,248(20.34)$ & $219,078(20.34)$ \\
\hline 4th quartile ( $\$ 63,000$ or more) & $114,521(11.55)$ & $131,230(12.94)$ & $133,571(12.40)$ \\
\hline \multicolumn{4}{|l|}{ Primary payer } \\
\hline Medicare & $643,010(63.18)$ & $652,143(62.84)$ & $692,608(63.02)$ \\
\hline Medicaid & $137,000(13.46)$ & $146,288(14.10)$ & $163,123(14.84)$ \\
\hline Private insurance & $142,543(14.00)$ & $139,120(13.40)$ & $128,603(11.70)$ \\
\hline Self-pay/no charge & $71,418(7.02)$ & $768,75(6.92)$ & $84,873(7.72)$ \\
\hline Other & $23,818(2.34)$ & $23,395(0.49)$ & $29,812(2.71)$ \\
\hline \multicolumn{4}{|l|}{ Hospital Region } \\
\hline Northeast & $170,206(16.70)$ & $175,398(16.87)$ & $181,739(16.52)$ \\
\hline Midwest & $250,323(24.56)$ & $261,053(25.11)$ & $268,176(24.37)$ \\
\hline South & $457,795(44.91)$ & $446,524(42.94)$ & $498,801(45.33)$ \\
\hline West & $140,952(13.83)$ & $156,850(15.08)$ & $151,661(13.78)$ \\
\hline \multicolumn{4}{|l|}{ Teaching status of hospital } \\
\hline Metropolitan non-teaching or non-metro & $730,087(71.63)$ & $721,206(69.36)$ & $742,700(67.49)$ \\
\hline Metropolitan teaching & $289,189(28.37)$ & $318,619(30.64)$ & $357,679(32.51)$ \\
\hline
\end{tabular}


The mean age for patients with COPD with ER visit in 2012 was 65.5 years, and $55 \%$ were female (Table 1). $73 \%$ lived in the metropolitan area, Medicare was the primary payer for $63 \%$ and $45 \%$ of all COPDhospitalizations occurred in hospitals located in the South (Table 1). The number of ED visits over time was stable (Fig. 1a) and income varied significantly by region (Fig. 1b), being lower in Southern US than other regions.

\section{Utilization and charges for COPD-related visits}

COPD ED visits were $0.79-0.82 \%$ of all ED visits (128.9 million, 129.0 million and 134.4 in 2009, 2010 and 2012) during the study period. The ED charges for visits with COPD as the primary diagnosis were $\$ 2.13$, \$2.32, and \$3.09 billion in 2009, 2010, and 2012 respectively (Additional file 1: Appendix 1). The total charges for ED and inpatient services in COPD patients who were admitted to the hospital with COPD as the primary diagnosis were $\$ 12.5, \$ 12.7$, and $\$ 14.2$ billion in the respective years (Additional file 1: Appendix 1). Total ED and inpatient charges with COPD diagnosis in any position (primary or other) were $\$ 121$ billion in 2012 (Additional file 1: Appendix 1).

Forty-nine percent were admitted to the hospital from the ED. Of those hospitalized with COPD as the primary diagnosis, $46 \%$ were discharged to home (Additional file 1: Appendix 2). Mean ED charges for ED visits with COPD as primary diagnosis were $\$ 2,812$ and mean total charges for admitted patients in 2012 were $\$ 29,043$. Mean length of hospital stay was 4.3 days (Additional file 1: Appendix 2). Outcomes by study year are shown in Additional file 1: Appendix 2.

\section{a. Total number of Ed visits over time by region}

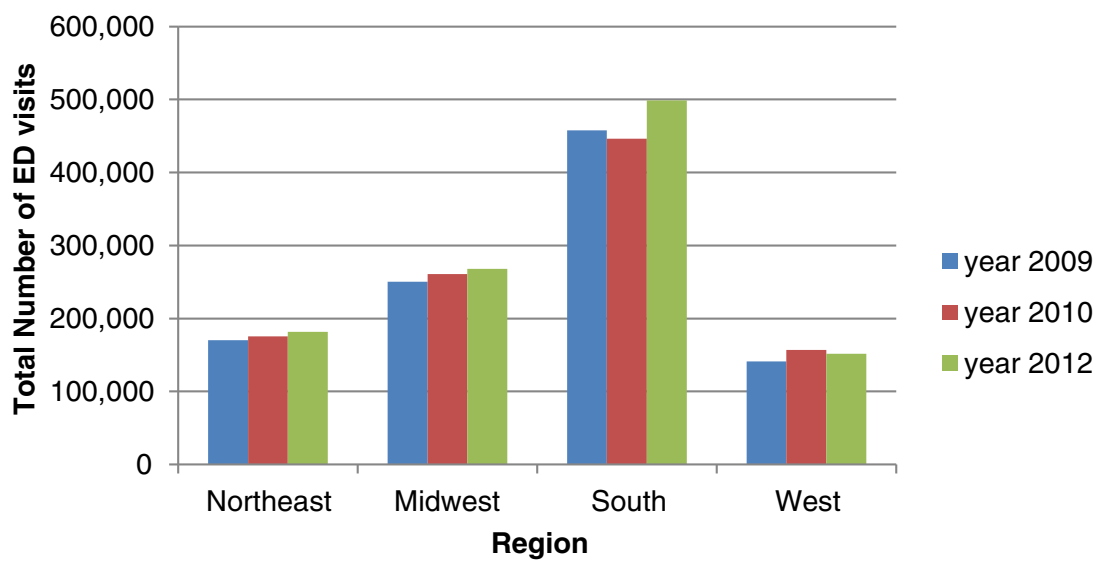

b. income categories by region

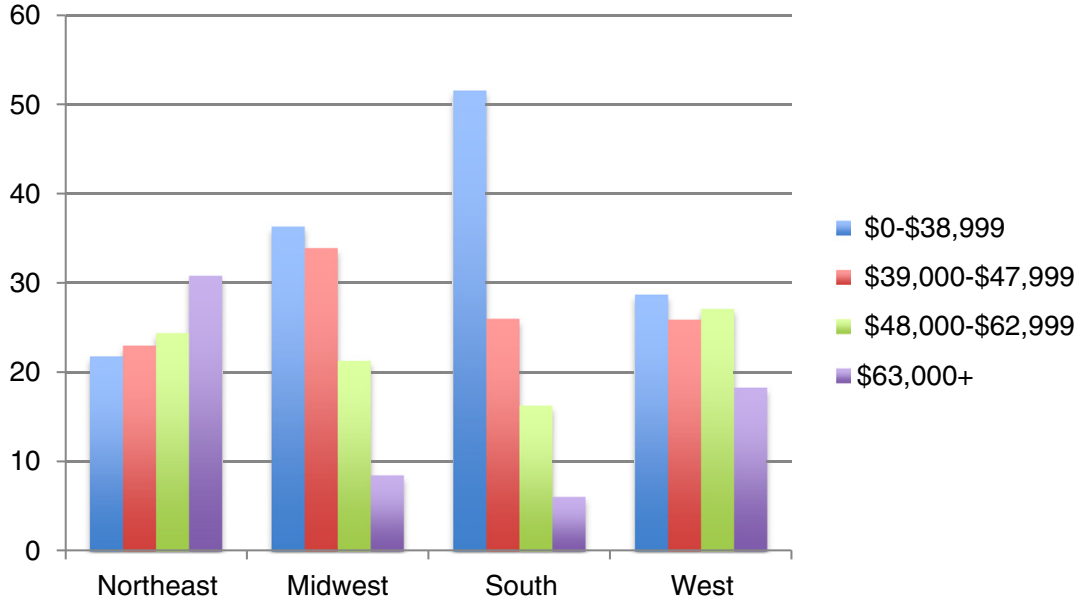

Fig. 1 Distribution of the total number of ED visits (a) and of income categories (b) with COPD as the primary diagnosis by region of residence.* Multivariable model adjusted for gender, race, Charlson score, beta-blockers, diuretics, ACE inhibitors and statins. X-axis represents the respective age, gender and race category and the $y$-axis hazard ratio. Each column represents the hazard ratio for that patient characteristic. Reference category is no allopurinol use (use $=0$ days), marked by hashed line passing through the hazard ratio of 1.00 . Error bars represent $95 \%$ confidence interval 
Predictors of ED charges and discharge disposition

Older age, male sex, residence in metropolitan area and hospital location in Midwest, South or West U.S. location, were each associated with higher charges for ED visit for COPD in multivariable-adjusted analyses (Additional file 1: Appendix 3).

In univariate analyses, several patient and hospital characteristics and comorbidities were associated with COPD-hospitalization after an ED visit (Additional file 1: Appendix 4). In multivariable-adjusted analyses, older age, higher median household income and metropolitan residence were associated with higher risk whereas male sex, Medicaid or self pay insurance status and hospital location in Midwest, South or Western U.S. were associated with lower risk of hospitalization after an ED visit for COPD (Table 2). Diabetes, hypertension, HF, hyperlipidemia, CHD were associated with 1.2-2.3 fold higher odds, renal failure with 3.1-fold and osteoarthritis with 5.0-fold odds of hospitalization in patients with ED visit with COPD as the primary diagnosis, respectively (Table 2).

\section{Hospitalization disposition and predictors}

In 2012, of all hospitalizations for COPD as the primary diagnosis, $65.4 \%$ were discharged home, $13.4 \%$ to skilled nursing/intermediate facilities, $17.2 \%$ to home health care and $1.1 \%$ died (Additional file 1: Appendix 5). Multivariable-adjusted analyses showed that older age and metropolitan residence were associated with lower odds, whereas male sex, payer other than Medicare, and Midwest, South or West U.S. hospital location were associated with higher odds of discharge to home (Table 3). Comorbidities except hyperlipidemia, hypertension, and gout were associated with lower-odds of discharge to home (Table 3); heart disease and osteoarthritis were not significantly associated. As expected, an opposite direction for associations was noted in multivariable-adjusted analyses for discharge to skilled facilities (Additional file 1: Appendix 6).

\section{Length of hospital stay and charges}

Multivariable-adjusted linear regression showed that older age and metropolitan location were associated with longer stay in patients hospitalized with COPD as the primary diagnosis whereas male sex, non-Medicare primary payer, hospital location other than Northeast were associated with shorter hospital stay (Table 4). Most comorbidities except hyperlipidemia, gout and hypertension were associated with longer hospital stay (Table 4); heart disease, diabetes and osteoarthritis were not significantly associated.

In multivariable-adjusted analyses, older age, higher income, metropolitan location, Western U.S. hospital location, and the presence of renal failure, HF and diabetes were associated higher total (ED + inpatient) hospital charges (Table 5). Male sex, non-Medicare primary payer, and a few comorbidities were associated with lower hospital charges (Table 5).

Sensitivity analyses examining the log of hospital stay (Additional file 1: Appendix 7), hospital stay when dichotomized at 2 days (Additional file 1: Appendix 8), or log of total hospital charges (Additional file 1: Appendix 9) showed similar results as above.

\section{Impact of co-existing asthma on outcomes}

When the main multivariable-adjusted models were additionally adjusted for the presence of asthma, we found that the odds of hospital admission from ED were not increased, $0.91(0.79,1.05 ; p=0.19)$, but odds of discharge to home were higher, $1.43(1.29,1.59) ; p<0.0001)$. Asthma was significantly associated with longer duration of hospital stay in those hospitalized, but hospital charges were not significantly different: beta coefficients $0.29(0.15,0.43 ; p<0.0001)$ and 947.4 $(-658.9,2553.6 ; p=0.24)$.

\section{Discussion}

In this study using the NEDS, a U.S. representative national sample, we studied utilization of ED and inpatient resources with COPD as the primary diagnosis. We found that COPD was associated with $>1$ million ED visits and over half a million hospitalizations in 2012. Our estimates for the overall number of ED visits and inpatient hospitalizations related to COPD are similar to those reported in a study that combined COPD and bronchiectasis [17]. A previous study of trends in COPD treatment in the ED showed higher concordance with treatment recommendations in the recent years [16], indicating that quality of COPD care in the ED may be improving over time. We also examined factors associated with health resource utilization and charges for ED and inpatient visits due to COPD. Several findings merit further discussion.

First, we found that several sociodemographic, comorbidity, and hospital factors were associated with the risk of hospitalization among COPD patients who presented to ED with COPD as the primary diagnosis. Previous studies have focused on pulmonary function status and COPD medications as predictors of COPD hospitalization and associated costs [22, 23], but did not examine socio-demographic and hospital characteristics in detail. Our study examined these key characteristics and made important observations.

We found that older age, median household income above $\$ 48,000$, metropolitan residence and the presence of comorbidities were each associated with higher risk of hospitalization. The association of older age with higher risk of COPD hospitalization is not surprising and confirms earlier similar findings from studies of smaller sample sizes [12, 24], now in a larger, representative U.S. sample. The association of higher median household income with a higher risk of COPD hospitalization/costs in interesting and extends a similar finding from other 
Table 2 Predictors of hospital admission among patients presenting to ER with COPD as the primary diagnosis using logistic regression

\begin{tabular}{|c|c|c|c|c|}
\hline & \multicolumn{2}{|l|}{ Univariate } & \multicolumn{2}{|c|}{ Multivariable-adjusted } \\
\hline & OR $(95 \% \mathrm{Cl})$ & $P$-value & OR (95 \% Cl) & $P$-value \\
\hline \multicolumn{5}{|l|}{ Age } \\
\hline$<50$ & Ref & & Ref & \\
\hline $50-<65$ & $2.01(1.92,2.09)$ & $<0.0001$ & $1.45(1.38,1.51)$ & $<0.0001$ \\
\hline $65-<80$ & $3.42(3.23,3.61)$ & $<0.0001$ & $1.67(1.57,1.77)$ & $<0.0001$ \\
\hline$\geq 80$ & $4.95(4.65,5.27)$ & $<0.0001$ & $1.90(1.77,2.03)$ & $<0.0001$ \\
\hline \multicolumn{5}{|l|}{ Gender } \\
\hline Female (ref) & Ref & & Ref & \\
\hline Male & $0.98(0.96,1.00)$ & 0.0309 & $0.91(0.89,0.93)$ & $<0.0001$ \\
\hline \multicolumn{5}{|l|}{ Median household income } \\
\hline 1st quartile $(<\$ 38,999)$ & Ref & & Ref & \\
\hline 2nd quartile $(\$ 39,000$ to $\$ 47,999)$ & $1.14(1.06,1.23)$ & 0.0009 & $1.08(1.00,1.18)$ & 0.0509 \\
\hline 3rd quartile ( $\$ 48,000$ to $\$ 62999)$ & $1.40(1.29,1.53)$ & $<0.0001$ & $1.17(1.07,1.29)$ & 0.0012 \\
\hline 4th quartile ( $\$ 63,000$ or more) & $2.08(1.86,2.33)$ & $<0.0001$ & $1.45(1.29,1.63)$ & $<0.0001$ \\
\hline \multicolumn{5}{|l|}{ Primary payer } \\
\hline Medicare (ref) & Ref & & Ref & \\
\hline Medicaid & $0.52(0.49,0.54)$ & $<0.0001$ & $0.91(0.86,0.96)$ & 0.0005 \\
\hline Private insurance & $0.63(0.60,0.66)$ & $<0.0001$ & $0.98(0.93,1.03)$ & 0.4990 \\
\hline Self-pay/no charge & $0.30(0.28,0.31)$ & $<0.0001$ & $0.70(0.66,0.74)$ & $<0.0001$ \\
\hline Other & $0.63(0.55,0.72)$ & $<0.0001$ & $1.04(0.93,1.15)$ & 0.5203 \\
\hline \multicolumn{5}{|l|}{ Patient location (residence) } \\
\hline Micropolitan/not metropolitan & Ref & & Ref & \\
\hline Metropolitan (large or small) & $1.70(1.54,1.89)$ & $<0.0001$ & $1.42(1.27,1.58)$ & $<0.0001$ \\
\hline \multicolumn{5}{|l|}{ Hospital Region } \\
\hline Northeast & Ref & & Ref & \\
\hline Midwest & $0.54(0.45,0.64)$ & $<0.0001$ & $0.60(0.51,0.71)$ & $<0.0001$ \\
\hline South & $0.66(0.56,0.79)$ & $<0.0001$ & $0.80(0.67,0.95)$ & 0.0106 \\
\hline West & $0.58(0.48,0.69)$ & $<0.0001$ & $0.63(0.52,0.76)$ & $<0.0001$ \\
\hline \multicolumn{5}{|l|}{ Teaching status of hospital } \\
\hline Metropolitan non-teaching or non-metropolitan & Ref & & Ref & \\
\hline Metropolitan teaching & $1.34(1.17,1.53)$ & $<0.0001$ & $1.14(0.99,1.30)$ & 0.0687 \\
\hline \multicolumn{5}{|l|}{ Comorbidities } \\
\hline CHD (ref: no) & $3.77(3.55,4.01)$ & $<0.0001$ & $1.89(1.80,1.99)$ & $<0.0001$ \\
\hline Hyperlipidemia (ref: no) & $4.30(3.98,4.64)$ & $<0.0001$ & $2.35(2.19,2.51)$ & $<0.0001$ \\
\hline Renal failure (ref: no) & $6.90(6.33,7.53)$ & $<0.0001$ & $3.10(2.83,3.39)$ & $<0.0001$ \\
\hline CHF (ref: no) & $3.96(3.73,4.21)$ & $<0.0001$ & $2.13(2.02,2.25)$ & $<0.0001$ \\
\hline Gout (ref: no) & $4.61(4.08,5.22)$ & $<0.0001$ & $1.87(1.64,2.14)$ & $<0.0001$ \\
\hline Diabetes (ref: no) & $2.24(2.14,2.33)$ & $<0.0001$ & $1.19(1.15,1.24)$ & $<0.0001$ \\
\hline Hypertension (ref: no) & $3.50(3.31,3.69)$ & $<0.0001$ & $1.93(1.84,2.02)$ & $<0.0001$ \\
\hline Osteoarthritis (ref: no) & $6.83(6.07,7.67)$ & $<0.0001$ & $5.02(4.42,5.70)$ & $<0.0001$ \\
\hline
\end{tabular}

CHD coronary heart disease, $C H F$ congestive heart failure, COPD chronic obstructive pulmonary disease, Significant odds ratios are in bold

chronic conditions $[25,26]$ to COPD. Since models were adjusted for insurance type, the income effect is independent of insurance status and type. It is possible that income reflects education level or health literacy level, both of which might impact the risk of hospitalization. The association of female sex with higher odds of COPD 
Table 3 Predictors of discharge to home among patients hospitalized with COPD as the primary diagnosis using logistic regression

\begin{tabular}{|c|c|c|c|c|}
\hline & \multicolumn{2}{|l|}{ Univariate } & \multicolumn{2}{|c|}{ Multivariable-adjusted } \\
\hline & OR $(95 \% \mathrm{Cl})$ & $P$-value & OR $(95 \% \mathrm{Cl})$ & $P$-value \\
\hline \multicolumn{5}{|l|}{ Age } \\
\hline$<50$ & Ref & & Ref & \\
\hline $50-<65$ & $0.72(0.67,0.77)$ & $<0.0001$ & $0.83(0.76,0.90)$ & $<0.0001$ \\
\hline $65-<80$ & $0.34(0.31,0.37)$ & $<0.0001$ & $0.51(0.46,0.56)$ & $<0.0001$ \\
\hline$\geq 80$ & $0.16(0.14,0.17)$ & $<0.0001$ & $0.25(0.23,0.28)$ & $<0.0001$ \\
\hline \multicolumn{5}{|l|}{ Gender } \\
\hline Female & Ref & & Ref & \\
\hline Male & $1.26(1.22,1.30)$ & $<0.0001$ & $1.22(1.18,1.26)$ & $<0.0001$ \\
\hline \multicolumn{5}{|l|}{ Median house hold income } \\
\hline 1st quartile $(<\$ 38,999)$ & Ref & & Ref & \\
\hline 2nd quartile $(\$ 39,000$ to $\$ 47,999)$ & $0.95(0.89,1.01)$ & 0.1216 & $1.03(0.96,1.10)$ & 0.3935 \\
\hline 3rd quartile ( $\$ 48,000$ to $\$ 62999)$ & $0.81(0.75,0.89)$ & $<0.0001$ & $0.97(0.89,1.06)$ & 0.4857 \\
\hline 4th quartile ( $\$ 63,000$ or more) & $0.65(0.59,0.72)$ & $<0.0001$ & $0.99(0.89,1.10)$ & 0.8347 \\
\hline \multicolumn{5}{|l|}{ Primary payer } \\
\hline Medicare & Ref & & Ref & \\
\hline Medicaid & $2.36(2.22,2.52)$ & $<0.0001$ & $1.30(1.22,1.39)$ & $<0.0001$ \\
\hline Private insurance & $2.84(2.60,3.10)$ & $<0.0001$ & $1.89(1.74,2.06)$ & $<0.0001$ \\
\hline Self-pay/no charge & $6.73(5.97,7.59)$ & $<0.0001$ & $3.01(2.62,3.45)$ & $<0.0001$ \\
\hline Other & $2.47(2.13,2.87)$ & $<0.0001$ & $1.46(1.23,1.74)$ & $<0.0001$ \\
\hline \multicolumn{5}{|l|}{ Patient location (residence) } \\
\hline Micropolitan/not metro & Ref & & Ref & \\
\hline Metropolitan (large or small) & $0.79(0.73,0.86)$ & $<0.0001$ & $0.88(0.81,0.96)$ & 0.0049 \\
\hline \multicolumn{5}{|l|}{ Hospital Region } \\
\hline Northeast & Ref & & Ref & \\
\hline Midwest & $1.55(1.36,1.76)$ & $<0.0001$ & $1.29(1.11,1.49)$ & 0.0007 \\
\hline South & $1.76(1.57,1.97)$ & $<0.0001$ & $1.52(1.33,1.73)$ & $<0.0001$ \\
\hline West & $1.83(1.59,2.11)$ & $<0.0001$ & $1.65(1.43,1.90)$ & $<0.0001$ \\
\hline \multicolumn{5}{|l|}{ Teaching status of hospital } \\
\hline Metropolitan non-teaching or non-metropolitan & Ref & & Ref & \\
\hline Metropolitan teaching & $0.92(0.83,1.02)$ & 0.1040 & $0.99(0.90,1.10)$ & 0.8999 \\
\hline \multicolumn{5}{|l|}{ Comorbidities } \\
\hline CHD (ref: no) & $0.79(0.77,0.82)$ & $<0.0001$ & $1.01(0.98,1.05)$ & 0.5676 \\
\hline Hyperlipidemia (ref: no) & $1.06(1.03,1.10)$ & 0.0008 & $1.22(1.18,1.27)$ & $<0.0001$ \\
\hline Renal failure (ref: no) & $0.60(0.57,0.62)$ & $<0.0001$ & $0.88(0.85,0.92)$ & $<0.0001$ \\
\hline CHF (ref: no) & $0.50(0.48,0.51)$ & $<0.0001$ & $0.67(0.65,0.69)$ & $<0.0001$ \\
\hline Gout (ref: no) & $0.87(0.80,0.94)$ & 0.0007 & $1.14(1.04,1.24)$ & 0.0036 \\
\hline Diabetes (ref: no) & $0.88(0.85,0.91)$ & $<0.0001$ & $0.91(0.88,0.94)$ & $<0.0001$ \\
\hline Hypertension (ref: no) & $0.88(0.85,0.90)$ & $<0.0001$ & $1.06(1.03,1.09)$ & 0.0001 \\
\hline Osteoarthritis (ref: no) & $0.84(0.80,0.89)$ & $<0.0001$ & $0.96(0.92,1.01)$ & 0.1430 \\
\hline Length of stay, in days & $0.83(0.83,0.84)$ & $<0.0001$ & $0.85(0.84,0.85)$ & $<0.0001$ \\
\hline
\end{tabular}

CHD coronary heart disease, CHF congestive heart failure, COPD chronic obstructive pulmonary disease, Significant odds ratios are in bold 
Table 4 Predictors of duration of hospital stay among patients with COPD who were admitted to the hospital after presenting to ED with COPD as the primary diagnosis using linear regression

\begin{tabular}{|c|c|c|c|c|}
\hline & \multicolumn{2}{|l|}{ Univariate } & \multicolumn{2}{|l|}{ Multivariable-adjusted } \\
\hline & B-estimate (95 \% Cl) & $P$-value & B-estimate (95 \% Cl) & $P$-value \\
\hline \multicolumn{5}{|l|}{ Age } \\
\hline$<50$ & Ref & & Ref & \\
\hline $50-<65$ & $0.52(0.43,0.61)$ & $<0.0001$ & $0.50(0.40,0.59)$ & $<0.0001$ \\
\hline $65-<80$ & $1.00(0.89,1.10)$ & $<0.0001$ & $0.82(0.70,0.93)$ & $<0.0001$ \\
\hline$\geq 80$ & $1.18(1.06,1.31)$ & $<0.0001$ & $0.85(0.73,0.98)$ & $<0.0001$ \\
\hline \multicolumn{5}{|l|}{ Gender } \\
\hline Female & Ref & & Ref & \\
\hline Male & $-0.28(-0.34,-0.23)$ & $<0.0001$ & $-0.29(-0.34,-0.24)$ & $<0.0001$ \\
\hline \multicolumn{5}{|l|}{ Median house hold income } \\
\hline 1st quartile $(<\$ 38,999)$ & Ref & & Ref & \\
\hline 2nd quartile $(\$ 39,000$ to $\$ 47,999)$ & $0.00(-0.10,0.10)$ & 0.9732 & $-0.03(-0.12,0.07)$ & 0.5973 \\
\hline 3rd quartile ( $\$ 48,000$ to $\$ 62999)$ & $0.05(-0.06,0.15)$ & 0.3623 & $-0.07(-0.17,0.03)$ & 0.1951 \\
\hline 4th quartile ( $\$ 63,000$ or more) & $0.40(0.20,0.59)$ & 0.0001 & $0.11(-0.05,0.28)$ & 0.1895 \\
\hline \multicolumn{5}{|l|}{ Primary payer } \\
\hline Medicare (ref) & Ref & & Ref & \\
\hline Medicaid & $-0.42(-0.52,-0.32)$ & $<0.0001$ & $-0.06(-0.16,0.04)$ & 0.2685 \\
\hline Private insurance & $-0.52(-0.61,-0.43)$ & $<0.0001$ & $-0.26(-0.34,-0.17)$ & $<0.0001$ \\
\hline Self-pay/no charge & $-1.19(-1.29,-1.09)$ & $<0.0001$ & $-0.74(-0.85,-0.64)$ & $<0.0001$ \\
\hline Other & $-0.61(-0.80,-0.42)$ & $<0.0001$ & $-0.26(-0.42,-0.10)$ & 0.0013 \\
\hline \multicolumn{5}{|l|}{ Patient location (residence) } \\
\hline Micropolitan/not metro & Ref & & Ref & \\
\hline Metro (large or small) & $0.35(0.23,0.47)$ & $<0.0001$ & $0.28(0.15,0.41)$ & $<0.0001$ \\
\hline \multicolumn{5}{|l|}{ Hospital Region } \\
\hline Northeast & Ref & & Ref & \\
\hline Midwest & $-0.79(-1.02,-0.57)$ & $<0.0001$ & $-0.67(-0.89,-0.45)$ & $<0.0001$ \\
\hline South & $-0.43(-0.65,-0.21)$ & 0.0001 & $-0.27(-0.48,-0.07)$ & 0.0103 \\
\hline West & $-0.80(-1.03,-0.58)$ & $<0.0001$ & $-0.76(-0.98,-0.54)$ & $<0.0001$ \\
\hline \multicolumn{5}{|l|}{ Teaching status of hospital } \\
\hline Metropolitan non-teaching or non-metropolitan & Ref & & Ref & \\
\hline Metropolitan teaching & $0.15(0.01,0.30)$ & 0.0363 & $0.03(-0.12,0.18)$ & 0.7276 \\
\hline \multicolumn{5}{|l|}{ Comorbidities } \\
\hline CHD (ref: no) & $0.16(0.10,0.21)$ & $<0.0001$ & $-0.03(-0.09,0.02)$ & 0.2051 \\
\hline Hyperlipidemia (ref: no) & $-0.20(-0.25,-0.14)$ & $<0.0001$ & $-0.30(-0.35,-0.25)$ & $<0.0001$ \\
\hline Renal failure (ref: no) & $0.51(0.43,0.58)$ & $<0.0001$ & $0.26(0.19,0.33)$ & $<0.0001$ \\
\hline CHF (ref: no) & $0.84(0.78,0.90)$ & $<0.0001$ & $0.73(0.66,0.79)$ & $<0.0001$ \\
\hline Gout (ref: no) & $-0.02(-0.17,0.13)$ & 0.8001 & $-0.24(-0.39,-0.08)$ & 0.0029 \\
\hline Diabetes (ref: no) & $0.12(0.06,0.17)$ & $<0.0001$ & $0.03(-0.02,0.08)$ & 0.2479 \\
\hline Hypertension (ref: no) & $-0.00(-0.06,0.05)$ & 0.9132 & $-0.15(-0.21,-0.09)$ & $<0.0001$ \\
\hline Osteoarthritis (ref: no) & $-0.01(-0.10,0.09)$ & 0.8771 & $-0.07(-0.16,0.03)$ & 0.1554 \\
\hline
\end{tabular}

CHD coronary heart disease, CHF congestive heart failure, COPD chronic obstructive pulmonary disease, Significant beta coefficients are in bold. A negative coefficient indicates a shorter hospital stay and positive coefficient, a longer hospital stay 
Table 5 Predictors of total (ED and inpatient) hospital charges in patients with COPD who were admitted to the hospital after presenting to ED with COPD as the primary diagnosis using linear regression

\begin{tabular}{|c|c|c|c|c|}
\hline & Univariate & & Multivariable-adjusted & \\
\hline & B-estimate (95\% Cl) & $P$-value & B-estimate $(95 \% \mathrm{Cl})$ & $P$-value \\
\hline Age & & & & \\
\hline$<50$ & Ref & & Ref & \\
\hline $50-<65$ & $3891.1(2985.4,4796.7)$ & $<0.0001$ & $3117.53(2219.7,4015.4)$ & $<0.0001$ \\
\hline $65-<80$ & $6652.1(5449.1,7855.1)$ & $<0.0001$ & $4176.16(2912.7,5439.7)$ & $<0.0001$ \\
\hline$\geq 80$ & $7109.4(5582.7,8636.1)$ & $<0.0001$ & $2974.40(1606.2,4342.6)$ & $<0.0001$ \\
\hline Gender & & & & \\
\hline Female & Ref & & Ref & \\
\hline Male & $-426.92(-1051.0,197.2)$ & 0.1797 & $-665.99(-1277.8,-54.2)$ & $<0.0001$ \\
\hline Median household income & & & & \\
\hline 1st quartile $(<\$ 38,999)$ & Ref & & Ref & \\
\hline 2nd quartile $(\$ 39,000$ to $\$ 47,999)$ & $371.8(-1261.3,2005.0)$ & 0.6550 & $-273.8(-1882.1,1334.5)$ & 0.7383 \\
\hline 3rd quartile (\$48,000 to $\$ 62999)$ & $4658.7(2156.6,7160.9)$ & 0.0003 & $2250.3(34.0,4466.6)$ & 0.0466 \\
\hline 4 th quartile ( $\$ 63,000$ or more) & $7493.74(3997.5,10990.0)$ & $<0.0001$ & $4614.2(1284.2,7944.2)$ & 0.0067 \\
\hline Primary payer & & & & \\
\hline Medicare (ref) & Ref & & Ref & \\
\hline Medicaid & $-2014.3(-3242.1,-786.4)$ & 0.0013 & $-963.2(-2007.8,81.3)$ & 0.0707 \\
\hline Private insurance & $-3725.8(-4972.1,-2479.4)$ & $<0.0001$ & $-2264.3(-3574.4,-954.1)$ & 0.0007 \\
\hline Self-pay/no charge & $-7134.2(-8265.9,-6002.6)$ & $<0.0001$ & $-4291.1(-5496.3,-3085.8)$ & $<0.0001$ \\
\hline Other & $-2313.6(-4674.1,47.0)$ & 0.0547 & $-2427.7(-4355.3,-500.1)$ & 0.0136 \\
\hline Patient location (residence) & & & & \\
\hline Micropolitan/not metro & Ref & & Ref & \\
\hline Metro (large or small) & $9681.5(7392.3,11970.6)$ & $<0.0001$ & $8000.2(5631.0,10369.3)$ & $<0.0001$ \\
\hline Hospital Region & & & & \\
\hline Northeast & Ref & & Ref & \\
\hline Midwest & $-5464.4(-9760.8,1168.1)$ & 0.0127 & $-3131.5(-7348.2,1085.1)$ & 0.1453 \\
\hline South & $257.9(-4333.9,4849.7)$ & 0.9122 & $3009.9(-1643.7,7663.6)$ & 0.2046 \\
\hline West & $17022.9(11248.1,22797.8)$ & $<0.0001$ & $18103.3(12310.9,23895.8)$ & $<0.0001$ \\
\hline Teaching status of hospital & & & & \\
\hline Metropolitan non-teaching or non-metropolitan & Ref & & Ref & \\
\hline Metropolitan teaching & $181.7(-3059.2,3422.7)$ & 0.9124 & $-461.9(-3862.1,2938.4)$ & 0.7898 \\
\hline Comorbidities & & & & \\
\hline CHD (ref: no) & $2094.6(1516.9,2672.4)$ & $<0.0001$ & $892.91(347.7,1438.1)$ & 0.0014 \\
\hline Hyperlipidemia (ref: no) & $-1748.2(-2335.2,-1161.2)$ & $<0.0001$ & $-2162.7(-2709.3,-1616.1)$ & $<0.0001$ \\
\hline Renal failure (ref: no) & $4756.1(3906.7,5605.5)$ & $<0.0001$ & $2414.5(1672.6,3156.4)$ & $<0.0001$ \\
\hline CHF (ref: no) & $7385.2(6410.1,8360.3)$ & $<0.0001$ & $6489.5(5491.6,7487.4)$ & $<0.0001$ \\
\hline Gout (ref: no) & $-1128.9(-2562.4,304.6)$ & 0.1225 & $-3127.6(-4587.4,-1667.8)$ & $<0.0001$ \\
\hline Diabetes (ref: no) & $1474.4(853.5,2095.3)$ & $<0.0001$ & $844.6(247.4,1441.7)$ & 0.0056 \\
\hline Hypertension (ref: no) & $329.1(-310.1,968.2)$ & 0.3125 & $-674.9(-1341.2,-8.53)$ & 0.0471 \\
\hline Osteoarthritis (ref: no) & $-2524.4(-3469.5,-1579.3)$ & $<0.0001$ & $-2153.9(-3023.9,-1283.9)$ & $<0.0001$ \\
\hline
\end{tabular}

CHD coronary heart disease, CHF congestive heart failure, COPD chronic obstructive pulmonary disease, Significant beta estimates are in bold 
hospitalization is consistent with a similar finding from Danish population-based study of 1.5-fold higher risk [27]. Medicaid or self-pay insurance status, hospital location in Midwest, South or Western U.S. were associated with lower risk of hospitalization after ED visit for COPD. The regional differences may be related to region-specific practices, differing severity of COPD and/or coexistent comorbidities by region, distance to nearest medical center etc. To our knowledge, our study is the one of the first U.S. studies to comprehensively examine the association of important socio-demographic, comorbidity and hospital characteristics and factors with COPD-hospitalization.

Comorbidities were risk factors for COPD hospitalizations. Diabetes, hypertension, heart failure, hyperlipidemia, and CHD were each associated with 1.2-2.3 fold higher odds of COPD hospitalization. Previous literature examining the association of comorbidities with COPD admission is somewhat contradictory. Coronary artery disease and diabetes mellitus were significant risk factors for COPD admission in some studies [28, 29], but other studies found no association of comorbidities with COPD readmission [30-33]. Potential reasons for differences in findings of previous studies are differences in comorbidities adjusted in the analyses, study settings, and omission of important confounders in some studies. General interventions such as physical rehabilitation can improve outcomes of patients hospitalized with COPD [34]. Other specific interventions and management strategies targeting these comorbidities (diabetes, hypertension, HF, CHD etc.) in patients with COPD might reduce COPD-associated inpatient utilization.

We found that renal failure was associated with 3.1times higher odds and osteoarthritis with 5.0-fold higher odds of hospitalization among COPD patients who presented to ED. To our knowledge, these findings are novel. Renal failure has been previously associated with higher mortality in hospitalized COPD patients, but risk of hospitalization was not assessed [35-37]. Whether the increased hospitalization risk is due to the presence of renal failure or its worsening during the treatment of COPD exacerbation with corticosteroids and antibiotics in the ED, cannot be determined from our study. Similar to our observation of $\$ 4,756$ unadjusted higher total charges in COPD patients with renal failure, a recent study by Manino et al. reported that the average allcause total health-care costs from the index date to 360 days after the index date were highest for patients with chronic kidney disease, by $\$ 41,288$ [38]. Therefore, future studies need to examine whether optimization of renal function by adequate hydration, medication management and optimization of renal function during a COPD flare and its treatment may help in reducing this risk of COPD hospitalization.
Osteoarthritis is associated with significant disability [39], loss of independence and higher health care utilization [40] in general. Difficulty in ambulation and daily activities due to concomitant osteoarthritis and associated frailty may contribute to a higher risk of hospitalization in COPD patients who also have difficulty in breathing. Use of assistive devices, exercises and self-management strategies reduce disability in osteoarthritis [41-43]; newer methods such as neuromuscular electrical stimulation may be helpful in some patients $[44,45]$. Future studies should examine if early diagnosis and optimal treatment of osteoarthritis in patients with COPD, focusing on inexpensive and commonly available non-surgical interventions for osteoarthritis, can reduce the risk of COPD hospitalization.

As noted above, our study findings of the association of various socio-demographic, comorbidity and hospital characteristics with COPD-hospitalization add to the current knowledge. Factors such as long term oxygen therapy, low health status, poor health related quality of life and inadequate physical activity [22] and body mass index, airflow obstruction, dyspnea, and exercise capacity (BODE) index [46] are associated with COPD hospitalization, and can predict hospital length of stay in and mortality in patients with COPD [47-50]. Our study identified additional risk factors for COPD hospitalization. This new knowledge can help clinicians risk stratify COPD patients and target those with poorest prognosis.

Another finding was that older age, diabetes, HF and renal failure were associated with lower odds and male sex with higher odds of discharge to home (vs. nursing home/facilities) in hospitalized COPD patients. These findings are not unexpected; however, we are unaware of any studies with a representative U.S. sample that have explored this aspect of COPD care. Thus, these findings are novel. It remains to be seen whether optimization of $\mathrm{HF}$, renal failure, and diabetes in COPD patients who are admitted to the hospital can increase the proportion discharged to home vs. skilled facilities.

Study findings must be interpreted considering study limitations. These findings are likely only applicable to ED-associated hospitalizations, not all hospitalizations. Due to the nature of NEDS database that captures data at the encounter level, rather than patient level, we are unable to examine risk factors for COPD readmissions, which are of interest clinically and for healthcare policy. We believe that at least some COPD admissions are readmissions. NEDS database does not link the ED visit to inpatient admission to another hospital, and we would likely miss this relatively uncommon event, since linkages of ED to hospitalization are at a hospital level. This underestimation is possible, but it is likely to be an uncommon or rare event. NEDS does not provide disease severity variables to adjust in the analyses, which can lead to residual 
confounding. Generalizability of findings to other countries may not be possible, since health care settings differ. Detailed assessments of COPD medications and their associations with COPD-related utilization would have provided additional insights; however, these data were not available in NEDs and this was beyond the scope of this study.

Our study has several strengths. NEDS is the largest, publically available U.S. sample of ED visits, therefore the findings are representative of and applicable to the U.S. population. We adjusted for several covariates and confounders including patient and hospital characteristics in patients with COPD to obtain unbiased estimates.

\section{Conclusions}

In conclusion, in this study of 2009-2012 NEDS data of patients presenting to the ED with COPD as the primary diagnosis, we studied patient discharge disposition from the ED and ED costs and for those admitted to the hospital, length of hospital stay, discharge disposition and costs. We found that older age, metropolitan residence and comorbidities (diabetes, HF, CHD, renal failure and osteoarthritis) were associated with higher risk of hospitalization and lower odds of discharge to home. Higher income was also associated with higher risk of hospitalization. We also identified other patient characteristics associated with hospital charges. Studies in the future should examine whether interventions targeting these modifiable factors can improve COPD outcomes.

\section{IRB approval}

The University of Alabama at Birmingham's Institutional Review Board approved this study and all investigations were conducted in conformity with ethical principles of research.

\section{Additional file}

Additional file 1: Appendix 1. Descriptive for the main ED visit-related outcomes with COPD diagnosis. Appendix 2. Patient Outcomes for those presenting to ED with COPD as the primary diagnosis. Appendix 3. Predictors of ED hospital charges among patients presenting to ER with COPD as the primary diagnosis using linear regression. Appendix 4. Characteristics of patients with COPD ED visits with and without hospitalization. Appendix 5. Outcomes of patients after hospital admission with COPD as primary or primary/secondary diagnosis. Appendix 6 . Predictors of Discharge to nursing home/skilled nursing facility among patients who were admitted to the hospital with COPD as the primary diagnosis after presenting to $E D$, using logistic regression. Appendix 7. Predictors of Log of duration of hospital stay among patients with COPD who were admitted to the hospital with COPD as the primary diagnosis after presenting to $E D$, using linear regression. Appendix 8. Predictors of Duration of stay (length of stay $>2$; reference, length of stay $\leq 2$ ) among patients who were admitted to the hospital with COPD as the primary diagnosis after presenting to ED, using logistic regression. Appendix 9. Predictors of log of Total hospital charges (ED plus inpatient) among patients with COPD who were admitted to the hospital using linear regression. (DOCX $58 \mathrm{~kb}$ )

\section{Competing interests}

There are no financial conflicts related directly to this study. JAS has received research grants from Takeda and Savient and consultant fees from Savient,

Takeda, Regeneron, Iroko, Merz, Bioiberica, Crealta, and Allergan pharmaceuticals. JAS serves as the principal investigator for an investigator-initiated study funded by Horizon pharmaceuticals through a grant to DINORA, Inc., a 501c3 entity. JAS is a member of the executive of OMERACT, an organization that receives arms-length funding from 36 companies; a member of the American College of Rheumatology's Guidelines Subcommittee of the Quality of Care Committee; and a member of the Veterans Affairs Rheumatology Field Advisory Committee. S.Y. has no conflicts to declare.

\section{Authors' contributions}

JAS was responsible for study conception and design, development of study protocol methods, review of statistical analyses and drafting the first complete version of the manuscript. SY performed the data abstraction, statistical analyses and made critical revisions to the manuscript. All authors read and approved the final manuscript, and made the decision to submit it for publication.

\section{Acknowledgements}

This material is the result of work supported by research funds from UAB Division of Rheumatology and the resources and use of facilities at the Birmingham VA Medical Center. JAS is also supported by grant from the National Institute of Arthritis, Musculoskeletal, and Skin Diseases (NIAMS) P50 AR060772.

\section{Grant support}

This material is the result of work supported by research funds from UAB Division of Rheumatology and the resources and use of facilities at the Birmingham VA Medical Center. JAS is also supported by grant from the National Institute of Arthritis, Musculoskeletal, and Skin Diseases (NIAMS) P50 AR060772.

\section{Author details}

'Medicine Service, Birmingham VA Medical Center, Birmingham, AL, USA.

${ }^{2}$ Department of Medicine at School of Medicine, and Division of Epidemiology at School of Public Health, University of Alabama at Birmingham (UAB), Faculty Office Tower 805B, 510 20th Street S,

Birmingham, AL 35294, USA. ${ }^{3}$ Department of Orthopedic Surgery, Mayo Clinic College of Medicine, Rochester, MN, USA.

Received: 10 September 2015 Accepted: 29 December 2015

Published online: 06 January 2016

References

1. Mannino DM, Buist AS. Global burden of COPD: risk factors, prevalence, and future trends. Lancet. 2007;370(9589):765-73.

2. Johnson NB, Hayes LD, Brown K, Hoo EC, Ethier KA. CDC National Health Report: leading causes of morbidity and mortality and associated behavioral risk and protective factors - United States, 2005-2013. MMWR. 2014; 63(Suppl-4):3-27.

3. Chronic Obstructive Pulmonary Disease (COPD). http://www.cdc.gov/copd/ data.htm

4. Ford ES, Murphy LB, Khavjou O, Giles WH, Holt JB, Croft JB. Total and state-specific medical and absenteeism costs of COPD among adults aged $>/=18$ years in the United States for 2010 and projections through 2020. Chest. 2015;147(1):31-45.

5. Wheaton AG, Cunningham TJ, Ford ES, Croft JB. Employment and activity limitations among adults with chronic obstructive pulmonary disease United States, 2013. MMWR Morb Mortal Wkly Rep. 2015;64(11):289-95.

6. van Boven JF, Vegter S, van der Molen T, Postma MJ. COPD in the working age population: the economic impact on both patients and government. Copd. 2013;10(6):629-39.

7. van Manen JG, Bindels PJ, Dekker FW, Bottema BJ, van der Zee JS, ljzermans CJ, et al. The influence of COPD on health-related quality of 
life independent of the influence of comorbidity. J Clin Epidemiol. 2003;56(12):1177-84.

8. Stahl E, Lindberg A, Jansson SA, Ronmark E, Svensson K, Andersson F, et al. Health-related quality of life is related to COPD disease severity. Health Qual Life Outcomes. 2005;3:56.

9. Okubadejo AA, Jones PW, Wedzicha JA. Quality of life in patients with chronic obstructive pulmonary disease and severe hypoxaemia. Thorax. 1996;51(1):44-7.

10. Donaldson GC, Seemungal TA, Bhowmik A, Wedzicha JA. Relationship between exacerbation frequency and lung function decline in chronic obstructive pulmonary disease. Thorax. 2002;57(10):847-52.

11. Seemungal TA, Donaldson GC, Paul EA, Bestall JC, Jeffries DJ, Wedzicha JA. Effect of exacerbation on quality of life in patients with chronic obstructive pulmonary disease. Am J Respir Crit Care Med. 1998;157(5 Pt 1):1418-22.

12. Kessler R, Faller M, Fourgaut G, Mennecier B, Weitzenblum E. Predictive factors of hospitalization for acute exacerbation in a series of 64 patients with chronic obstructive pulmonary disease. Am J Respir Crit Care Med. 1999;159(1):158-64.

13. Garcia-Aymerich J, Monso E, Marrades RM, Escarrabill J, Felez MA, Sunyer J, et al. Risk factors for hospitalization for a chronic obstructive pulmonary disease exacerbation. EFRAM study. Am J Respir Crit Care Med. 2001;164(6):1002-7.

14. Tsai CL, Clark S, Cydulka RK, Rowe BH, Camargo Jr CA. Factors associated with hospital admission among emergency department patients with chronic obstructive pulmonary disease exacerbation. Acad Emerg Med. 2007;14(1):6-14.

15. Tsai CL, Delclos GL, Camargo Jr CA. Emergency department case volume and patient outcomes in acute exacerbations of chronic obstructive pulmonary disease. Acad Emerg Med. 2012;19(6):656-63.

16. Tsai CL, Sobrino JA, Camargo Jr CA. National study of emergency department visits for acute exacerbation of chronic obstructive pulmonary disease, 1993-2005. Acad Emerg Med. 2008;15(12):1275-83.

17. Ford ES. Hospital discharges, readmissions, and emergency department visits for chronic obstructive pulmonary disease or bronchiectasis among US adults: findings from the Nationwide Inpatient Sample 2001-2012 and Nationwide Emergency Department Sample 2006-2011. Chest. 2015;147(4):989-98.

18. Mannino DM, Homa DM, Akinbami LJ, Ford ES, Redd SC. Chronic obstructive pulmonary disease surveillance-United States, 1971-2000. MMWR Surveill Summ. 2002;51(6):1-16.

19. HCUP Nationwide Emergency Department Sample (NEDS). Healthcare Cost and Utilization Project (HCUP). 2007, 2008, 2009. http:/www.hcup-us.ahrq.gov/ nedsoverview.jsp. In: Agency for Healthcare Research and Quality, Rockville, MD.

20. Introduction to the HCUP Nationawide Emergency Department Sample (NEDS) 2012. http://www.hcup-us.ahrq.gov/db/nation/neds/NEDS_Introduction_2012.jpp. In:: Agency for Healthcare Research and Quality, Rockville, MD.

21. Menzin J, Boulanger L, Marton J, Guadagno L, Dastani H, Dirani R, et al. The economic burden of chronic obstructive pulmonary disease (COPD) in a U.S. Medicare population. Respir Med. 2008;102(9):1248-56.

22. Bahadori K, FitzGerald JM. Risk factors of hospitalization and readmission of patients with COPD exacerbation-systematic review. Int J Chron Obstruct Pulmon Dis. 2007;2(3):241-51.

23. Blais $L$, Forget $A$, Ramachandran $S$. Relative effectiveness of budesonide/ formoterol and fluticasone propionate/salmeterol in a 1-year, populationbased, matched cohort study of patients with chronic obstructive pulmonary disease (COPD): effect on COPD-related exacerbations, emergency department visits and hospitalizations, medication utilization, and treatment adherence. Clin Ther. 2010;32(7):1320-8.

24. Soler-Cataluna JJ, Martinez-Garcia MA, Roman Sanchez P, Salcedo E, Navarro $\mathrm{M}$, Ochando R. Severe acute exacerbations and mortality in patients with chronic obstructive pulmonary disease. Thorax. 2005;60(11):925-31.

25. Lokhandwala T, Khanna R, West-Strum D. Hospitalization burden among individuals with autism. J Autism Dev Disord. 2012;42(1):95-104.

26. Sharma M, Sonig A, Ambekar S, Nanda A. Discharge dispositions, complications, and costs of hospitalization in spinal cord tumor surgery: analysis of data from the United States Nationwide Inpatient Sample, 2003-2010. J Neurosurg Spine. 2014;20(2):125-41.

27. Prescott E, Bjerg AM, Andersen PK, Lange P, Vestbo J. Gender difference in smoking effects on lung function and risk of hospitalization for COPD: results from a Danish longitudinal population study. Eur Respir J. 1997; 10(4):822-7.

28. Lau AC, Yam LY, Poon E. Hospital re-admission in patients with acute exacerbation of chronic obstructive pulmonary disease. Respir Med. 2001;95(11):876-84.
29. Miravitlles M, Guerrero T, Mayordomo C, Sanchez-Agudo L, Nicolau F, Segu JL. Factors associated with increased risk of exacerbation and hospital admission in a cohort of ambulatory COPD patients: a multiple logistic regression analysis. The EOLO Study Group. Respir Int Rev Thorac Dis. 2000; 67(5):495-501

30. Cao Z, Ong KC, Eng P, Tan WC, Ng TP. Frequent hospital readmissions for acute exacerbation of COPD and their associated factors. Respirology. 2006; 11(2):188-95.

31. Garcia-Aymerich J, Farrero E, Felez MA, Izquierdo J, Marrades RM, Anto JM, et al. Risk factors of readmission to hospital for a COPD exacerbation: a prospective study. Thorax. 2003;58(2):100-5.

32. Pouw EM, Ten Velde GP, Croonen BH, Kester AD, Schols AM, Wouters EF. Early non-elective readmission for chronic obstructive pulmonary disease is associated with weight loss. Clin Nutr. 2000;19(2):95-9.

33. Groenewegen $\mathrm{KH}$, Schols AM, Wouters EF. Mortality and mortality-related factors after hospitalization for acute exacerbation of COPD. Chest. 2003;124(2):459-67.

34. Spencer LM. Rehabilitation following hospitalization in patients with COPD: Can it reduce readmissions? Respirology. 2015;20(3):357-8.

35. Alaithan AM, Memon JI, Rehmani RS, Qureshi AA, Salam A. Chronic obstructive pulmonary disease: hospital and intensive care unit outcomes in the Kingdom of Saudi Arabia. Int J Chron Obstruct Pulmon Dis. 2012;7:819-23.

36. Duffy S, Barnett S, Civic B, Mamary AJ, Criner GJ. Risk of death by comorbidity prompting rehospitalization following the initial COPD hospitalization. J COPD F. 2015;2(1):17-22.

37. Hasegawa W, Yamauchi Y, Yasunaga $H$, Sunohara M, Jo T, Matsui H, et al. Factors affecting mortality following emergency admission for chronic obstructive pulmonary disease. BMC Pulm Med. 2014;14:151.

38. Mannino DM, Higuchi K, Yu TC, Zhou H, Li Y, Tian H, et al. Economic Burden of COPD in the Presence of Comorbidities. Chest. 2015;148(1):138-50.

39. Jordan J, Luta G, Renner J, Dragomir A, Hochberg M, Fryer J. Knee pain and knee osteoarthritis severity in self-reported task specific disability: the Johnston County Osteoarthritis Project. J Rheumatol. 1997;24(7):1344-9.

40. Stamm TA, Pieber K, Blasche G, Dorner TE. Health care utilisation in subjects with osteoarthritis, chronic back pain and osteoporosis aged 65 years and more: mediating effects of limitations in activities of daily living, pain intensity and mental diseases. Wien Med Wochenschr. 2014;164(7-8):160-6.

41. Penninx BW, Messier SP, Rejeski WJ, Williamson JD, DiBari M, Cavazzini C, et al. Physical exercise and the prevention of disability in activities of daily living in older persons with osteoarthritis. Arch Intern Med. 2001;161(19):2309-16.

42. McCormack R. Prevention of disability in daily activities in older persons with knee osteoarthritis. Clin J Sport Med. 2002;12(6):405.

43. Kjeken I, Darre S, Slatkowsky-Cristensen B, Hermann M, Nilsen T, Eriksen CS, et al. Self-management strategies to support performance of daily activities in hand osteoarthritis. Scand J Occup Ther. 2013;20(1):29-36.

44. Seto H, Ikeda H, Hisaoka H, Kurosawa H. Effect of heat- and steamgenerating sheet on daily activities of living in patients with osteoarthritis of the knee: randomized prospective study. J Orthop Sci. 2008;13(3):187-91.

45. Imoto AM, Peccin MS, Teixeira LE, Silva KN, Abrahao M, Trevisani VF. Is neuromuscular electrical stimulation effective for improving pain, function and activities of daily living of knee osteoarthritis patients? A randomized clinical trial. Sao Paulo Med J. 2013;131(2):80-7.

46. Ong KC, Earnest A, Lu SJ. A multidimensional grading system (BODE index) as predictor of hospitalization for COPD. Chest. 2005;128(6):3810-6.

47. Diamantea F, Kostikas K, Bartziokas K, Karakontaki F, Tsikrika S, Pouriki S, et al. Prediction of hospitalization stay in COPD exacerbations: the AECOPD-F score. Respir Care. 2014;59(11):1679-86.

48. Almagro P, Calbo E, Ochoa De Echaquen A, Barreiro B, Quintana S, Heredia $J \mathrm{~L}$, et al. Mortality after hospitalization for COPD. Chest. 2002;121(5):1441-8.

49. Esteban C, Quintana JM, Aburto M, Moraza J, Arostegui I, Espana PP, et al. The health, activity, dyspnea, obstruction, age, and hospitalization: prognostic score for stable COPD patients. Respir Med. 2011;105(11):1662-70.

50. Moberg M, Vestbo J, Martinez G, Williams JE, Ladelund S, Lange P, et al. Validation of the i-BODE index as a predictor of hospitalization and mortality in patients with COPD Participating in pulmonary rehabilitation. Copd. 2014;11(4):381-7. 